\title{
Comparison of the Use of Shock Index and Modified Early Obstetric Warning Score in COVID-19 Obstetric Emergency Patients as ICU Care Parameters
}

\author{
Sri Wahyuni \\ Midwifery Studies Program, Hasanuddin University, Makassar, Indonesia \\ Corresponding author email: sriayhura1212@gmail.com
}

\section{Siti Maisuri T Chalid}

Department Obstetry Ginecology Hasanuddin University, Makassar, Indonesia

Email: maisurichalid@gmail.com

\author{
Nugraha Utama Pelupessy \\ Department Obstetry Ginecology Hasanuddin University, Makassar, Indonesia \\ Email:nugrahup@gmail.com \\ Sharvianty Arifuddin \\ Department Obstetry Ginecology Hasanuddin University, Makassar, Indonesia \\ Email: sharviantyarifuddin@gmail.com \\ Irfan Idris \\ Department Of Physiology, Faculty of Medicine, Hasanuddin University, Makassar, Indonesia \\ Email: irfanfaal@gmail.com
}

\author{
Andi Nilawati Usman \\ Midwifery Study Program, Hasanuddin University, Makasar, Indonesia \\ Email: nilawatiandi@pasca.unhas.ac.id
}

\begin{abstract}
The physiological parameters included in the Modified Early Obstetric Warning Score (MEOWS) table have been selectively selected so that they cover all the standard observations in the NEWS table with the addition of several parameters that are specifically. The population in this study were all pregnant women who were in RSIA Siti Khadijah I Makassar and RSUP Dr. Wahidin Sudirohusodo Makassar. The results showed that there was no significant difference between the shock index and the incidence of shock $(p=0.418)$. The difference in frequency between the shock index and the incidence of shock in the ICU was 1 patient who was pregnant. Based on shock index with high and low categories did not differ significantly $(p=0.418)$. The data also shows that the frequency of pregnant women who are in shock is higher, namely 44 people (57.9\%) compared to those who are not in shock, namely 32 people (42.1\%). There was no significant difference between the shock index and the incidence of shock $(p=0.112)$. The difference in frequency between the shock index and the incidence of shock in the ICU was 5 patients with pregnant women. Shock frequency based on the MEOWS index was not significantly different $(p=0.112)$.

Keywords---COVID-19, emergency patients, ICU care, MEOWS, shock index
\end{abstract}




\section{Introduction}

Pregnancy, childbirth, and the puerperium can be complicated by conditions that can cause severe maternal morbidity and require intensive care unit (ICU) care. Critical illness can complicate $0.3 \%$ of deliveries. Abnormalities in obstetrics occupy the most indications of obstetric patients receiving ICU care such as hypertension in pregnancy, especially preeclampsia, and sepsis while medical disorders (non-obstetrics) that may require ICU care the most are respiratory failure which can be triggered by asthma, pneumonia, lung disease. Chronic pulmonary and pulmonary thromboembolism, rheumatic heart valve disease, complicated urinary tract infections, endocrine disorders, and trauma. Most obstetric patients receive ICU care during the postpartum period (Prawirohardjo et al., 2008).

The goal of treating obstetric patients in the ICU is to provide intensive monitoring and physiological support for patients with life-threatening conditions with potentially reversible conditions. Management of obstetric patients in the ICU is very complex and requires collaboration between obstetricians, intensivists, and other multidisciplinary. Management of obstetric patients in the ICU has its challenges because there are anatomical and physiological changes during pregnancy. From a social perspective, most obstetric patients are young, in the reproductive age range, and most are in good health. Therefore, obstetric patients admitted to the ICU have a better prognosis compared to other non-obstetric patients admitted to the ICU. The mortality of obstetric patients in the ICU ranged from 2-3\%. Comprehensive care in the ICU is expected to reduce maternal mortality (Libert et al., 2016).

To quote one of the WHO's mottos in addressing maternal mortality, There is a story behind every maternal death or life-threatening complication. Understanding the lessons to be learned can help to avoid such outcomes, so that better knowledge of the characteristics of obstetric patients in the ICU can prevent and reduce maternal mortality and morbidity. Very few studies have been conducted on obstetric patients in ICU, especially in developing countries (Yonke \& Leeman, 2013). According to the World Health Organization (WHO), maternal mortality in developing countries in 2017 was 230 per 100,000 live births compared to 16 per 100,000 live births in developed countries. There are large differences between countries, with some countries having very high maternal mortality ratios of around 1000 per 100,000 live births (WHO, 2012).

Based on the 2015 Indonesian Health Demographic Survey (IDHS), the MMR in Indonesia is 305 per 100,000 live births. The main causes of maternal death are hypertension in pregnancy and obstetric emergencies. This cause can be minimized if the quality of Antenatal Care is implemented properly. The direct causes of maternal death in Indonesia are bleeding by $28 \%$, eclampsia by $24 \%$, infection by $11 \%$, postpartum complications by $11 \%$, abortion by $5 \%$, prolonged labor by $5 \%$, and other causes by $11 \%$ (Ministry of Health RI, 2018).

Based on data obtained from the South Sulawesi Provincial Health Office in 2016. MMR was recorded at 116 people, the most common cause was bleeding 72 people (62.06\%), eclampsia 19 people (16.37), infection 5 people $(4,31 \%)$, and other 20 people $(17.24 \%)$. while in 2017 it was 114 people, where the most causes were bleeding as many as 59 people $(51.75 \%)$, infection by 8 people $(7.01 \%)$, and others as many as 12 people $(10.52 \%)$. Obstetric care of ICU patients is a serious complication that can occur in various obstetric conditions. Treatment for obstetric bleeding can be managed effectively by focusing on the cause of the obstetric bleeding. Pregnant women who die from obstetric hemorrhage will show signs of hemorrhagic shock. This shock is almost always fatal for both mother and fetus, especially if rescue action is taken too late. Hemorrhagic shock in pregnant women is caused by an acute decrease in circulating blood volume (Friedman, 2015).

The physiological parameters included in the Modified Early Obstetric Warning Score (MEOWS) table have been selectively selected so that they cover all the standard observations in the NEWS table with the addition of several parameters that are specifically related to pregnancy and postpartum mothers. The physiological parameters contained in the NEWS table are systolic and diastolic blood pressure, pulse, respiration, temperature, oxygen saturation, and degree of consciousness. These parameters are standard observation parameters recommended by NICE. Our bodies try to compensate for this bleeding. This compensatory mechanism aims to protect vital organs (brain and heart) to sustain life. All efforts should be aimed at restoring adequate tissue oxygenation as soon as possible. The outcome of our action is very dependent on accurate early diagnosis and fast and aggressive treatment to restore hemodynamics of the mother's body which is very dependent on 3 things, namely giving oxygen, stopping the source of bleeding, and replacing lost bleeding (De Kock et al., 2008).

The use of a modified Early warning score for use in pregnant women and postpartum women will assist in early identification, therapy, and referral of mothers with critical conditions to facilities that can handle these conditions and is highly recommended because in many cases the early warning signs of shock in the mother are not present identified (Singh et al., 2016). The advantage of the Modified Early Obstetric Warning Score (MEOWS) is that the faster the recognition of danger signs during the observation period, maternal morbidity and mortality can be 
reduced. Shock index and Modified Early Obstetric Warning Score (MEOWS) can be used to estimate whether a person will fall into a critical condition or not. There are no studies that explain which score is better used for scoring patients who will fall into shock. The Modified Early Obstetric Warning Score (MEOWS) was used to assess the signs of worsening in pregnant women by monitoring the physiological parameters of the mother. The Modified Early Obstetric Warning Score (MEOWS) is used to standardize the physiological measurements we normally take. The results of our observations will be transferred to a score table that has a critical limit where medical intervention needs to be carried out. While the drawback is that there is a small change in the combination of physiological variables that are measured, which can detect a worsening of the mother's condition more quickly if the assessment is based on individual physiological variables. Early detection will trigger a series of interventions that aim to restore physiological functions that have decreased or facilitate patient referrals to people who are more capable of carrying out further treatment (Torabi et al., 2016; Ryan et al., 2017).

One of the reasons the researchers chose the title is because the shock index (IS) is used when the score is used to assess the onset of an obstetric emergency that occurs in trauma patients. The assessment is based on the patient's vital signs where a calculation is made between the patient's heart rate and blood pressure. This score is an initial modality that can be used to identify patients who are at risk for massive bleeding. So from the above background, the authors want to know "Comparison of the Use of Shock Index and Modified Early Obstetric Warning Score in Obstetric Emergency Patients as ICU Treatment Parameters".

\section{Research Methods}

The research design used was a retrospective cohort, a research design in which researchers grouped exposed and unexposed, then observed for a certain time to see if there was no effect or disease. Researchers took the outcome data of mothers with ICU care experiencing shock and not shock then calculated the shock index and modified the early obstetric warning score. The gold standard used for the diagnostic criteria for shock is the classification of hemorrhagic shock based on the American College of Surgeon Committee on Trauma (ACS). The shock categories included in this study were second, third, and fourth-degree shock. This study will be tested with diagnostic tests so that the sensitivity, specificity, PPV, NPV, LR, and accuracy values are obtained. This study was conducted by taking data on mothers with obstetric emergencies at RSIA Siti Khadijah I Makassar and RSUP Dr. Wahidin Sudirohusodo Makassar and is estimated to be carried out for 12 months or until the sample target is met after being approved by the Health Research Ethics Committee, Faculty of Medicine, Hasanuddin University Makassar. The population in this study were all postpartum mothers who were in the postpartum room at RSIA Siti Khadijah I Makassar and RSUP Dr. Wahidin Sudirohusodo Makassar. The sample in this study were some postpartum mothers who experienced obstetric emergencies and was in the puerperium ward of RSIA Siti Khadijah I Makassar and RSUP Dr. Wahidin Sudirohusodo Makassar used purposive sampling using inclusion and exclusion criteria of 77 people. Data from both groups were recorded on the data collection form and entered in the master table, then the distribution and frequency of the data were presented in textual and tabular form. The data were analyzed using diagnostic tests so that the values of sensitivity, specificity, PPV, NPV, LR, and accuracy were obtained. The test is considered significant if $\mathrm{P}<0.05$.

\section{Results and Discussion}

The research was carried out in April-June 2021 with ethical approval recommendations number: 1849/UN4.14.1/TP.02.02/2021. This type of research is a retrospective cohort. The population in this study were all postpartum mothers who were in the postpartum room at RSIA Siti Khadijah I Makassar and RSUP Dr. Wahidin Sudirohusodo Makassar. The sample in this study were some postpartum mothers who experienced obstetric emergencies and was in the puerperium ward of RSIA Siti Khadijah I Makassar and RSUP Dr. Wahidin Sudirohusodo Makassar used purposive sampling using inclusion and exclusion criteria of 77 people. Data from both groups were recorded on the data collection form and entered in the master table, then the distribution and frequency of the data were presented in textual and tabular form. The data were analyzed using diagnostic tests so that the values of sensitivity, specificity, PPV, NPV, LR, and accuracy were obtained. The test is considered significant if $P$ $<0.05$. All data processing and analysis were carried out using the SPSS 25 statistical data processing program for windows. 
Table 1

Research sample distribution data

\begin{tabular}{lll}
\hline No & Hospital & Total \\
\hline 1 & RSIA Siti Khadijah I Makassar & 26 Sample \\
2 & RSUP Dr. Wahidin Sudirohusodo Makassar & 50 Sample \\
\hline
\end{tabular}

Source: Primary Data 2021

Based on table 1 above, it shows that of the 76 people who were used as samples, the researchers researched 2 places where RSIA Siti Khadijah I Makassar as many as 26 samples then RSUP Dr. Wahidin Sudirohusodo Makassar as many as 50 samples.

Table 2

Frequency of shock events (ICU) by comorbid

\begin{tabular}{|c|c|c|c|}
\hline & \multicolumn{2}{|c|}{ Shock incident } & \multirow{3}{*}{ Total } \\
\hline & Shock & No Shock & \\
\hline & $\mathrm{n}(\%)$ & $\mathrm{n}(\%)$ & \\
\hline Gravid & $31(69.9)$ & $14(31.1)$ & 45 \\
\hline PEB & $8(36.4)$ & $14(63.6)$ & 22 \\
\hline Severe hypokalemia & $1(100)$ & $0(0)$ & 1 \\
\hline KET & $1(100)$ & $0(0)$ & 1 \\
\hline Placenta Previa & $2(100)$ & $0(0)$ & 2 \\
\hline Hipoalbuminemia & $0(0)$ & $1(100)$ & 1 \\
\hline SLE & $1(100)$ & $0(0)$ & 1 \\
\hline Abortus Inkomplit & $0(0)$ & $3(100)$ & 3 \\
\hline Total & 44 & 32 & 76 \\
\hline
\end{tabular}

Source: Primary Data 2021

Based on the table above, it shows that of the 76 people who were used as samples, the dominant comorbid gravid mother experienced shock where there were 31 people (69.6\%) experiencing shock 14 people $(31.1 \%)$ not experiencing shock and 8 people $(36.4 \%)$ with a history of PEB experienced shock and 14 people $63.6 \%$ ) did not experience shock.

Table 3

Frequency of shock occurrence (Obstetrics) by comorbid

\begin{tabular}{llll}
\hline \multirow{2}{*}{ Comorbid } & \multicolumn{2}{c}{ Shock incident } & \multirow{2}{*}{ Total } \\
\cline { 2 - 3 } & Shock & No Shock & \\
\cline { 2 - 3 } & $\mathrm{n}(\%)$ & $\mathrm{n}(\%)$ & 45 \\
Gravid & $35(77.8)$ & $10(22.2)$ & 22 \\
PEB & $17(77.3)$ & $5(22.7)$ & 1 \\
Severe hypokalemia & $1(100)$ & $0(0)$ & 1 \\
KET & $1(100)$ & $0(0)$ & 2 \\
Placenta Previa & $2(100)$ & $0(0)$ & 1 \\
Hipoalbuminemia & $0(0)$ & $1(100)$ & 1 \\
SLE & $1(100)$ & $0(0)$ & 3 \\
Abortus Inkomplit & $3(100)$ & $0(0)$ & 76 \\
Total & 60 & 16 & \\
\hline
\end{tabular}

Source: Primary Data 2021

Based on the table above, it shows that of the 76 people who were used as samples, the dominant mothers with shock (obstetrics) with comorbid gravid experienced shock as many as 35 people (77.8\%), and 10 people (22.2\%) did not experience shock and PEB who experienced a shock. experienced shock 17 people (77.3\%) and 5 people (22.7\%) did not experience shock. 
Table 4

Shock potential (MEOWS) based on comorbid

\begin{tabular}{|c|c|c|c|}
\hline \multirow{3}{*}{ Komorbid } & \multicolumn{2}{|c|}{ Risk of Shock } & \multirow{3}{*}{ Total } \\
\hline & Tall & No Shock & \\
\hline & $\mathrm{n}(\%)$ & $\mathrm{n}(\%)$ & \\
\hline Gravid & $29(64.4)$ & $16(35.6)$ & 45 \\
\hline PEB & $3(13.6)$ & $19(86.4)$ & 22 \\
\hline Hipokalemia Berat & $1(100)$ & $0(0)$ & 1 \\
\hline KET & $1(100)$ & $0(0)$ & 1 \\
\hline Placenta Previa & $1(50)$ & $1(50)$ & 2 \\
\hline Hipoalbuminemia & $1(100)$ & $0(0)$ & 1 \\
\hline SLE & $1(100)$ & $0(0)$ & 1 \\
\hline Abortus Inkomplit & $2(66.7)$ & $1(33.3)$ & 3 \\
\hline Total & 39 & 37 & 76 \\
\hline
\end{tabular}

Source: Primary Data 2021

Based on the table above, it shows that of the 76 people who were used as samples, the dominant mother with potential shock (MEOWS) with comorbid gravid experienced high shock as many as 29 people (64.4\%) and 16 people (35.6\%) experienced low shock and PEB. who experienced high shock 3 people $(13.6 \%)$ and 19 people $(86.4 \%)$ did not experience shock. In this study, the age of the respondents in this study was more in the age group of 20-35 years, namely $76.6 \%$. This is in accordance with the demographic conditions of the Indonesian population where the structure of Indonesia's population includes the structure of the young population with the most being of reproductive age. Based on the parity of the respondents studied more in multigravida that is $50.6 \%$. Based on the education of the respondents, the respondents with a high school education level were $51.9 \%$ and the dominant mother who worked as an IRT was $63.6 \%$.

In this study, the sensitivity value of the shock index in predicting shock was $82.5 \%$ with a specificity value of $89.6 \%$ while the MEOWS sensitivity was $86.5 \%$ with a specificity value of $93.4 \%$. the occurrence of shock, but the PPV value of the MEOWS is lower than the shock index, namely $81.5 \%$ compared to the PPV of the shock index of $82.5 \%$, so that the false positive rate from the use of the MEOWS score is greater than the use of the shock index. For NPV, the MEOWS NPV value is better than the shock index, which is $93.4 \%$ so the false-negative rate of using MEOWS is lower than the shock index. The false-positive assessment of the high MEOWS may be caused by one of the assessments of the MEOWS score that almost all patients have, both in shock and non-shock patients, causing the MEOWS score to be higher at the time of measurement. From the results of the study, it was also obtained that the Pvalue $<0.05$ both on the shock index score and MEOWS where there was a correlation between the shock index and MEOWS in predicting the occurrence of shock (Primadewi \& Diwyami, 2021; Zulfa et al., 2021).

In this study, the sensitivity of the MEOWS score was higher than the shock index in shock patients. This is probably because some of the measurements contained in the MEOWS are also measurements that are needed for the criteria for the diagnosis of shock so that when the patient is in shock where the measurement is meaningful, the MEOWS value automatically becomes meaningful.

The likelihood ratio + indicates the number of times the probability of positive test results in the diseased population group is compared to a + test result in the non-diseased population group. A good test must have a large $\mathrm{LR}+$, because the + test results in the diseased population group must be greater than in the non-diseased group. The negative likelihood ratio indicates the number of times a negative test result occurs in the diseased group more often than in the nondiseased group. The smaller the negative LR, the better the test because negative test results should be less common in the diseased group than in the nondiseased group. A positive Likelihood ratio value of 1 is not useful as a diagnostic test, 1-2 is considered less, $2-5$ tests are considered quite useful, 6-10 is considered good, $>10$ is considered very good as a diagnostic test. A negative Likelihood ratio value of $0.5-1$ is not useful as a diagnostic test, $0.2-0.5$ test is considered sufficient, $0.1-0.2$ is considered good, $<0.1$ is considered very good as a diagnostic test.

In the IS study on the incidence of shock, it was found that LR+ 5.088 and LR-0.007. The interpretation of these results is that if we use the shock index as a predictor of shock, it is likely that we will find patients with a high shock index result in shock cases compared to the non-diseased group, while LR-0.00 indicates that the less likely we are to find patients with a high shock index in patients who are not diseased. This value indicates that the shock index is very well used as a diagnostic tool because it has an LR+ value of more than 6 and an LR- of less than 0.01 . In the MEOWS study on the incidence of shock, it was found that LR+ 4.02 and LR-0.00. The LR+ results on MEOWS 
measurements were lower than those with IS which indicates that we will often find patients with high MEOWS interpretations who are not in shock compared to IS measurements. The LR-0.00 indicates that we are less likely to find patients with high IS in patients who are not in shock (Borovac-Pinheiro et al., 2016; Birkhahn et al., 2003).

From this study, the accuracy of the IS examination was $87.2 \%$ and the MEOWS examination accuracy was $86.5 \%$. What is meant by accuracy in this study is how big the ability of the measuring instrument used to measure patients who are in shock and patients who are not in shock. Judging from the accuracy, both IS and MEOWS are good measuring tools that can be used as predictors of shock. Shock index has a better accuracy value than MEOWS. This is due to the high number of false positives that appear on examination using MEOWS. Although statistically, the IS accuracy value is better than MEOWS, for diagnostic purposes, a measuring instrument that provides better sensitivity is considered more meaningful for diagnostic purposes.

Several factors may be the cause of higher false positives and lower LR+ in MEOWS compared to SI namely MEOWS pain score. In the MEOWS scoring system, if a patient feels pain, a score of three will be given, while most patients who come with bleeding during pregnancy do experience abdominal pain. In the MEOWS scoring system, there is no specific difference in the scale of pain felt by patients, such as using the Visual Analog Scale (VAS) so that for every patient who experiences abdominal pain, the MEOWS category will be included with a score of three, both pain with a VAS scale of two and a VAS scale of eight. Pain assessment on MEOWS measurements in pregnant bleeding patients makes MEOWS scores higher even though the patient has not experienced a shock. If you want to do further research, it can be proposed to categorize the pain scale so that the data becomes more specific and minimizes the possibility of false positives in the sample.

In the MEOWS scoring system, the presence of blood discharge will be given a score of three, while patients with bleeding in early pregnancy tend to have this complaint which causes the MEOWS value to be higher which causes higher false positives. This scoring does not specify how much blood comes out so that the blood that comes out, both in small and large amounts, is still counted the same. In a study conducted by Carle et al. who used the MEOWS score as a predictor of maternal mortality in the Intensive Care Unit (ICU), the area on the ROC curve was 0.96 which showed MEOWS is a good measuring tool as a predictor of maternal mortality in the ICU. These results are similar to the results we obtained in our study, namely the ROC MEOWS area of 0.985 which indicates that MEOWS is a good predictor of the incidence of shock (Friedman, 2015).

From the ROC curve of shock index and MEOWS as a predictor of shock, the ROC area of IS was 0.957 and MEOWS was 0.971 . The ROC area above 0.8 is considered very good to be used as a measuring tool that can predict the occurrence of shock with a p-value $<0.05$. Because MEOWS has a high sensitivity, the use of MEOWS as a diagnostic is recommended because the examination is not difficult and does not need to use complex tools. Saturation measuring devices and urine tests can be done in almost every hospital. Meanwhile, if there is no saturation tool, for example in the area or in a Puskesmas, the use of the shock index can be considered as a measuring tool because the parameters measured are shorter and have fairly good sensitivity. The advantage of this study is that there are no studies that directly compare the shock index and MEOWS to obstetric emergencies as a parameter of ICU care (Sripadma et al., 2020; Zhang et al., 2020).

The drawback of this study is that researchers only took measurements when the patient was admitted to the hospital and did not take measurements when the patient was being treated so that hemodynamic changes that occurred during the procedure that could establish a diagnosis of shock were not recorded. Weaknesses are also found in the calculation of the shock index where the patient comes in with unmeasured blood pressure or unmeasured pulse, so it must be excluded from this case even though it is a case of shock. In the calculation of the shock index there is a score that is experienced by almost all samples, thereby increasing the MEOWS score and causing the false positive rate to be high. Another weakness is that there are samples that are referrals from the Puskesmas that have been installed with infusion so that when the patient arrives they have received fluids, thus affecting the validity of the shock index and MEOWS assessments.

Table 5

Shock index sensitivity and specificity test results

\begin{tabular}{llll}
\hline \multirow{2}{*}{ Shock Index } & \multicolumn{2}{c}{ Risk of Shock } & Total \\
\cline { 2 - 3 } & Shock & No Shock & \\
\hline Tall & $22(28.9)$ & $19(25.0)$ & 41 \\
Low & $22(28.9)$ & $13(17.1)$ & 35 \\
Total & 44 & 32 & 76 \\
Negative Predictive value (NPV) & & $17.10 \%$ & \\
\hline
\end{tabular}




\begin{tabular}{ll}
\hline Positive Predictive value (PPV) & $53.65 \%$ \\
P & \\
Sensitivitas & $50 \%$ \\
\hline Source: Primary Data 2021 &
\end{tabular}
Source: Primary Data 2021

Based on the table above, it shows that the sensitivity test results obtained as many as 22 people (28.9\%) with a high shock index experiencing shock and 19 people (25.0\%) and a low shock index 22 people (28.9\%) not experiencing a shock.

Table 6

Frequency distribution of research variables

\begin{tabular}{lll}
\hline Research variable & Total (n) & Low $(\%)$ \\
\hline Shock Indeks & & \\
Tall & 39 & 51,3 \\
Low & 37 & 48,7 \\
MEOWS & & \\
Tall & 40 & 52,6 \\
Low & 36 & 47,4 \\
Emergency Obstetrics (Shock) & & \\
Shock & 39 & 51,3 \\
No Shock & 37 & 48,7 \\
total & 76 & 100 \\
\hline Source: Primary Data 2021 & &
\end{tabular}

Table 6 shows that of the 76 respondents who were used as samples, 39 people $(51.3 \%)$ had a high shock index and 37 people $(48.7 \%)$ had a low shock index. Meanwhile, 40 people (52.6\%) had high MEOWS and 36 people (47.4\%) had low MEOWS 39 people (51.3\%) had an emergency obstetric shock and 37 people did not (48. 7\%)

Table 7

Shock Incidence (ICU) by age

\begin{tabular}{|c|c|c|c|c|c|}
\hline \multirow[b]{2}{*}{ Age } & & \multicolumn{2}{|c|}{ Risk of Shock } & \multirow[b]{2}{*}{ Total } & \multirow[b]{2}{*}{ P-value } \\
\hline & & $\begin{array}{l}\text { Tall } \\
\mathrm{n}(\%)\end{array}$ & $\begin{array}{l}\text { No Shock } \\
\mathrm{n}(\%)\end{array}$ & & \\
\hline \multirow[t]{3}{*}{ Age } & $<20$ & $2(2.6)$ & $0(0.0)$ & $2(2.6)$ & \\
\hline & $20-35$ & $32(42.1)$ & $26(34.2)$ & $58(76.3)$ & $0.418 *$ \\
\hline & $>=35$ & $10(13.2)$ & $6(7.9)$ & $16(21.1)$ & \\
\hline Total & & $44(57.9)$ & $32(42.1)$ & $76(100)$ & \\
\hline
\end{tabular}

The table 7 shows that most patients are in the age group 20-35 years (76.3\%), followed by the age group 35 years $(21.1 \%)$. The highest incidence of shock was in the age group of 20-35 years, as many as 32 people (42.1\%) of the total patients, 76 people. The second highest frequency was in those aged 35 years, as many as 10 people (13.2\%) of the total patients. However, the data also showed that, all patients in the $<20$ years age group experienced shock, as many as 2 people. Analysis using Kruskall Wallis showed that the incidence of shock was higher at age 20-35 years followed by 36.75 and $<20$ years. This shows that the age group of 20-35 years shows a higher probability of shock. However, there were no statistical differences in the incidence of shock by age.

Table 8

Shock Incidence (ICU) by parity

\begin{tabular}{|c|c|c|c|c|c|}
\hline \multirow[b]{2}{*}{ Parity } & & \multicolumn{2}{|c|}{ Risk of Shock } & & \multirow[t]{2}{*}{ Risk of Shock } \\
\hline & & $\begin{array}{l}\text { Tall } \\
\mathrm{n}(\%)\end{array}$ & $\begin{array}{l}\text { Tall } \\
\mathrm{n}(\%)\end{array}$ & Total & \\
\hline parity & Primipara & $18(23.7)$ & $12(15.8)$ & $30(39.5)$ & \\
\hline
\end{tabular}




\begin{tabular}{llllll}
\hline & Multipara & $20(26.3)$ & $18(23.7)$ & $38(50.0)$ & $0.490^{*}$ \\
Total & Grandemultipara & $6(7.9)$ & $2(2.6)$ & $8(10.5)$ & \\
& Count & $44(57.9)$ & $32(42.1)$ & $76(100.0)$ &
\end{tabular}

* The Kruskall Wallis test showed that the mean rates of shock based on parity were, primipara 37.30, multipara 40.50, and grandemultipara 32.00.

Table 8 shows that the highest parity category out of 76 pregnant women was the multiparous group, which was 38 people $(50.0 \%)$, followed by the primipara group, which was 30 people $(39.5 \%)$. The highest frequency of shock was in the multiparous category, ie 20 people $(26.3 \%)$ followed by the primipara category, namely 18 people $(23.7 \%)$ of the total pregnant women. However, the data also show that, in the grandemultipara category, more people experienced shock than those who did not.

Analysis using Kruskall Wallis showed that the highest shock rate was in the category of multiparas 40.50 following primiparas 37.50 and grandemultiparas 32.00 . This shows that the multiparous category shows a higher probability of shock. However, there was no statistical difference in the incidence of shock by parity.

Table 9

Differences in the frequency of shock between shock index and ICU

\begin{tabular}{lllllll}
\hline \multicolumn{2}{l}{ Shock Index } & \multicolumn{3}{l}{ Shock Index (ICU) } & \multicolumn{3}{l}{ Frequency Difference } & \\
\cline { 1 - 5 } Tall & Low & Shock & No Shoct & Shock & No Shoct & P-value \\
\hline $\mathrm{n}(\%)$ & $\mathrm{n}(\%)$ & $\mathrm{n}(\%)$ & $\mathrm{n}(\%)$ & $\mathrm{n}$ & $\mathrm{n}$ & \\
$41(53.9)$ & $35(46.1)$ & $44(57.9)$ & $32(42.1)$ & 1 & 1 & $0.418^{*}$ \\
\hline
\end{tabular}

Chi-Square test

Table 9 shows that there is no significant difference between the shock index and the incidence of shock ( $\mathrm{p}=0.418)$. The difference in frequency between the shock index and the incidence of shock in the ICU is 1 patient pregnant women

Table 10

Differences in the incidence of shock based on the shock index

\begin{tabular}{|c|c|c|c|c|}
\hline \multirow[b]{2}{*}{ Shock Index } & \multicolumn{2}{|c|}{ Shock ICU } & & \multirow[t]{2}{*}{ P-value } \\
\hline & Shock & No Shock & Total & \\
\hline Indeks Shock Tall & $22(28.9)$ & $19(26.0)$ & $41(53.9)$ & \\
\hline Low & $22(28.9)$ & $13(17.1)$ & $35(46.1)$ & $0.418^{*}$ \\
\hline Total & $44(57.9)$ & $32(42.1)$ & $76(100)$ & \\
\hline
\end{tabular}

Chi-square test

Table 10 shows that the frequency of shock events based on the shock index in the high and low categories was not significantly different $(\mathrm{p}=0.418)$. The data also showed that the frequency of pregnant women who were in shock was higher, namely 44 people (57.9\%) compared to those who were not in shock, namely 32 people (42.1\%).

Table 11

Differences in the frequency of shock events between shock index and ICU

\begin{tabular}{|c|c|c|c|c|c|c|}
\hline \multicolumn{2}{|c|}{ Index MEOWS } & \multicolumn{2}{|c|}{ Shock Incident (ICU) } & \multicolumn{2}{|c|}{ Frequency Difference } & P-value \\
\hline $\begin{array}{l}\text { Tall } \\
\text { n (\%) }\end{array}$ & $\begin{array}{l}\text { Low } \\
\mathrm{n}(\%)\end{array}$ & $\begin{array}{l}\text { Shock } \\
\mathrm{n}(\%)\end{array}$ & $\begin{array}{l}\text { No Shock } \\
\mathrm{n}(\%)\end{array}$ & $\begin{array}{l}\text { Shock } \\
\text { n }\end{array}$ & $\begin{array}{l}\text { No Shock } \\
\mathrm{n}\end{array}$ & \\
\hline $39(51.3)$ & $37(48.7)$ & $44(57.9)$ & $32(42.1)$ & 5 & 5 & $0.112 *$ \\
\hline
\end{tabular}

Chi Square test

Table 11 shows that there is no significant difference between the shock index and the incidence of shock $(\mathrm{p}=0.112)$. The difference in frequency between the shock index and the incidence of shock in the ICU is 5 pregnant women patients 
Table 12

Differences in the incidence of shock based on the MEOWS indeks index

\begin{tabular}{llllll}
\hline \multicolumn{2}{c}{ Index MEOWS } & \multicolumn{2}{c}{ Shock ICU } & Total & P-value \\
\cline { 3 - 4 } & & Shock & No Shock & & \\
\hline MEOWS & Tall & $26(34.2)$ & $13(17.1)$ & $39(51.3)$ & \\
& Low & $18(23.7)$ & $19(25.0)$ & $37(48.7)$ & $0.112 *$ \\
Total & & $44(57.9)$ & $32(42.1)$ & $76(100.0)$ & \\
\hline
\end{tabular}

Chi-Square Test

Table 12 shows that the frequency of shock based on the MEOWS index was not significantly different $(\mathrm{p}=0.112)$. However, it can be seen that the MEOWS index category has a higher incidence of shock. In this study, the age of the respondents in this study was more in the age group of 20-35 years, namely $76.6 \%$. This is in accordance with the demographic conditions of the Indonesian population where the structure of Indonesia's population includes the structure of the young population with the most being of reproductive age. Based on the parity of the respondents studied more in multigravida that is $50.6 \%$. Based on the education of the respondents, the respondents with a high school education level were $51.9 \%$ and the dominant mother who worked as an IRT was $63.6 \%$.

In this study, the sensitivity value of the shock index in predicting shock was $82.5 \%$ with a specificity value of $89.6 \%$ while the MEOWS sensitivity was $86.5 \%$ with a specificity value of $93.4 \%$. the occurrence of shock, but the PPV value of the MEOWS is lower than the shock index, namely $81.5 \%$ compared to the PPV of the shock index of $82.5 \%$ so that the false positive rate from the use of the MEOWS score is greater than the use of the shock index. For NPV, the MEOWS NPV value is better than the shock index, which is $93.4 \%$ so the false-negative rate of using MEOWS is lower than the shock index. The false-positive assessment of the high MEOWS may be caused by one of the assessments of the MEOWS score that almost all patients have, both in shock and non-shock patients, causing the MEOWS score to be higher at the time of measurement. From the results of the study, it was also obtained that the Pvalue $<0.05$ both on the shock index score and MEOWS where there was a correlation between the shock index and MEOWS in predicting the occurrence of shock (Cook, 2014; Edwards et al., 2015).

In this study, the sensitivity of the MEOWS score was higher than the shock index in shock patients. This is probably because some of the measurements contained in the MEOWS are also measurements that are needed for the criteria for the diagnosis of shock so that when the patient is in shock where the measurement is meaningful, the MEOWS value automatically becomes meaningful. The likelihood ratio + indicates the number of times the probability of positive test results in the diseased population group is compared to a + test result in the non-diseased population group. A good test must have a large LR + , because the + test results in the diseased population group must be greater than in the non-diseased group. The negative likelihood ratio indicates the number of times a negative test result occurs in the diseased group more often than in the nondiseased group. The smaller the negative LR, the better the test because negative test results should be less common in the diseased group than in the nondiseased group. A positive Likelihood ratio value of 1 is not useful as a diagnostic test, 1-2 is considered less, 2-5 tests are considered quite useful, $6-10$ is considered good, $>10$ is considered very good as a diagnostic test. A negative Likelihood ratio value of 0.5-1 is not useful as a diagnostic test, $0.2-0.5$ test is considered sufficient, 0.10.2 is considered good, $<0.1$ is considered very good as a diagnostic test.

In the IS study on the incidence of shock, it was found that LR+ 5.088 and LR-0.007. The interpretation of these results is that if we use the shock index as a predictor of shock, it is likely that we will find patients with a high shock index result in shock cases compared to the non-diseased group, while LR-0.00 indicates that the less likely we are to find patients with a high shock index in patients who are not diseased. This value indicates that the shock index is very well used as a diagnostic tool because it has an LR+ value of more than 6 and an LR- of less than 0.01 . In the MEOWS study on the incidence of shock, it was found that LR+ 4.02 and LR-0.00. The LR+ results on MEOWS measurements were lower than those with IS which indicates that we will often find patients with high MEOWS interpretations who are not in shock compared to IS measurements. The LR-0.00 indicates that we are less likely to find patients with high IS in patients who are not in shock.

From this study, the accuracy of the IS examination was $87.2 \%$ and the MEOWS examination accuracy was $86.5 \%$. What is meant by accuracy in this study is how big the ability of the measuring instrument used to measure patients who are in shock and patients who are not in shock. Judging from the accuracy, both IS and MEOWS are good measuring tools that can be used as predictors of shock. Shock index has a better accuracy value than MEOWS. This is due to the high number of false positives that appear on examination using MEOWS. Although statistically, 
the IS accuracy value is better than MEOWS, for diagnostic purposes, a measuring instrument that provides better sensitivity is considered more meaningful for diagnostic purposes.

Several factors may be the cause of higher false positives and lower LR+ in MEOWS compared to SI namely MEOWS pain score. In the MEOWS scoring system, if a patient feels pain, a score of three will be given, while most patients who come with bleeding during pregnancy do experience abdominal pain. In the MEOWS scoring system, there is no specific difference in the scale of pain felt by patients, such as using the Visual Analog Scale (VAS) so that for every patient who experiences abdominal pain, the MEOWS category will be included with a score of three, both pain with a VAS scale of two and a VAS scale of eight. Pain assessment on MEOWS measurements in pregnant bleeding patients makes MEOWS scores higher even though the patient has not experienced a shock. If you want to do further research, it can be proposed to categorize the pain scale so that the data becomes more specific and minimizes the possibility of false positives in the sample.

In the MEOWS scoring system, the presence of blood discharge will be given a score of three, while patients with bleeding in early pregnancy tend to have this complaint which causes the MEOWS value to be higher which causes higher false positives. This scoring does not specify how much blood comes out so that the blood that comes out, both in small and large amounts, is still counted the same. In a study conducted by Carle et al. who used the MEOWS score as a predictor of maternal mortality in the Intensive Care Unit (ICU), the area on the ROC curve was 0.96 which showed MEOWS is a good measuring tool as a predictor of maternal mortality in the ICU. These results are similar to the results we obtained in our study, namely the ROC MEOWS area of 0.985 which indicates that MEOWS is a good predictor of the incidence of shock (Friedman, 2015).

From the ROC curve of shock index and MEOWS as a predictor of shock, the ROC area of IS was 0.957 and MEOWS was 0.971 . The ROC area above 0.8 is considered very good to be used as a measuring tool that can predict the occurrence of shock with a p-value $<0.05$. Because MEOWS has a high sensitivity, the use of MEOWS as a diagnostic is recommended because the examination is not difficult and does not need to use complex tools. Saturation measuring devices and urine tests can be done in almost every hospital. Meanwhile, if there is no saturation tool, for example in the area or in a puskesmas, the use of the shock index can be considered as a measuring tool because the parameters measured are shorter and have fairly good sensitivity. The advantage of this study is that there are no studies that directly compare the shock index and MEOWS to obstetric emergencies as a parameter of ICU care.

The drawback of this study is that researchers only took measurements when the patient was admitted to the hospital and did not take measurements when the patient was being treated so that hemodynamic changes that occurred during the procedure that could establish a diagnosis of shock were not recorded. Weaknesses are also found in the calculation of the shock index where the patient comes in with unmeasured blood pressure or unmeasured pulse, so it must be excluded from this case even though it is a case of shock. In the calculation of the shock index there is a score that is experienced by almost all samples, thereby increasing the MEOWS score and causing the false positive rate to be high. Another weakness is that there are samples that are referrals from the puskesmas that have been installed with infusion so that when the patient arrives they have received fluids, thus affecting the validity of the shock index and MEOWS assessments.

\section{Conclusion}

Based on the results of the research and discussion, it can be concluded that MEOWS has a better sensitivity to be used as a predictor of a shock compared to the shock index. MEOWS is better used than the shock index to predict a person will fall into a state of shock (Diagnosis) while the shock index is better than the MEOWS to predict a person will not fall into a state of shock (Screening).

\section{Acknowledgments}

The researcher would like to express his gratitude to all the staff who helped him by allowing him to do his research from April to June at RSUP, Dr.Wahidin Sudirohusodo, and RSIA. Khadija 1st makassar south Sulawesi.

\section{References}

Birkhahn, R. H., Gaeta, T. J., Van Deusen, S. K., \& Tloczkowski, J. (2003). The ability of traditional vital signs and shock index to identify ruptured ectopic pregnancy. American journal of obstetrics and gynecology, 189(5), 1293-1296. https://doi.org/10.1067/S0002-9378(03)00663-X 
Borovac-Pinheiro, A., Pacagnella, R. C., Morais, S. S., \& Cecatti, J. G. (2016). Standard reference values for the shock index during pregnancy. International Journal of Gynecology \& Obstetrics, 135(1), 11-15. https://doi.org/10.1016/j.ijgo.2016.03.024

Cook, C. A. (2014). Implementing the modified early obstetric warning score (MEOWS) to detect early signs of clinical deterioration and decrease maternal mortality. Journal of Obstetric, Gynecologic \& Neonatal Nursing, 43, S22. https://doi.org/10.1111/1552-6909.12392

De Kock, J., Heyns, T., \& Van Rensburg, G. H. (2008). The ABC of haemorrhagic shock in the pregnant woman.

Edwards, S. E., Grobman, W. A., Lappen, J. R., Winter, C., Fox, R., Lenguerrand, E., \& Draycott, T. (2015). Modified obstetric early warning scoring systems (MOEWS): validating the diagnostic performance for severe sepsis in women with chorioamnionitis. American journal of obstetrics and gynecology, 212(4), 536-e1. https://doi.org/10.1016/j.ajog.2014.11.007

Friedman, A. M. (2015). Maternal early warning systems. Obstetrics and Gynecology Clinics, 42(2), 289-298.

Libert, N., Harrois, A., \& Duranteau, J. (2016). Haemodynamic coherence in haemorrhagic shock. Best Practice \& Research Clinical Anaesthesiology, 30(4), 429-435. https://doi.org/10.1016/j.bpa.2016.11.002

Prawirohardjo, S., SAIFUDDIN, A. B., RACHIMHADHI, T., \& WIKNJOSASTRO, G. H. (2008). Ilmu kebidanan.

Primadewi, K., \& Diwyami, N. P. (2021). Correlation of knowledge and family support to compliance with iron (fe) tablet consumption for pregnant women in preventing anemia: new normal COVID-19 era in working area of health centers south kuta. International Journal of Health Sciences, 5(2), 189-201. https://doi.org/10.29332/ijhs.v5n2.1405

Ryan, H. M., Jones, M. A., Payne, B. A., Sharma, S., Hutfield, A. M., Lee, T., ... \& von Dadelszen, P. (2017). Validating the performance of the modified early obstetric warning system multivariable model to predict maternal intensive care unit admission. Journal of Obstetrics and Gynaecology Canada, 39(9), 728-733. https://doi.org/10.1016/j.jogc.2017.01.028

Singh, A., Guleria, K., Vaid, N. B., \& Jain, S. (2016). Evaluation of maternal early obstetric warning system (MEOWS chart) as a predictor of obstetric morbidity: a prospective observational study. European Journal of Obstetrics \& Gynecology and Reproductive Biology, 207, 11-17. https://doi.org/10.1016/j.ejogrb.2016.09.014

Sripadma, P. V., Rai, A., \& Wadhwa, C. (2020). Postpartum atypical posterior reversible encephalopathy syndrome in a COVID-19 patient-an obstetric emergency. Journal of Stroke and Cerebrovascular Diseases, 29(12), 105357. https://doi.org/10.1016/j.jstrokecerebrovasdis.2020.105357

Torabi, M., Mirafzal, A., Rastegari, A., \& Sadeghkhani, N. (2016). Association of triage time shock index, modified shock index, and age shock index with mortality in emergency severity index level 2 patients. The American journal of emergency medicine, 34(1), 63-68. https://doi.org/10.1016/j.ajem.2015.09.014

World Health Organization. (2012). WHO recommendations for the prevention and treatment of postpartum haemorrhage. World Health Organization.

Yonke, N., \& Leeman, L. M. (2013). First-trimester surgical abortion technique. Obstetrics and Gynecology Clinics, 40(4), 647-670.

Zhang, J., Xu, D., Xie, B., Zhang, Y., Huang, H., Liu, H., ... \& Yuan, S. (2020). Poor-sleep is associated with slow recovery from lymphopenia and an increased need for ICU care in hospitalized patients with COVID-19: A retrospective cohort study. Brain, behavior, and immunity, 88, 50-58. https://doi.org/10.1016/j.bbi.2020.05.075

Zulfa, S. Z., Emilia, O., \& Hidayat, A. (2021). Midwives preparation to provide delivery services in independent midwife practice during COVID-19 pandemic. International Journal of Health Sciences, 5(3), 344-351. https://doi.org/10.53730/ijhs.v5n3.1554 